\title{
MÉTODO DA ADSORÇÃo DE CÉSIO PARA DETERMINAÇÃO DA CARGA ES- TRUTURAL EM SOLOS ALTAMENTE INTEMPERIZADOS ${ }^{(1)}$
}

\author{
OSCARLINA LÚCIA DOS SANTOS WEBER ${ }^{(2,6)}$; JOSÉ. CARLOS CHITOLINA ${ }^{(3)}$; \\ OTÁVIO ANTÔNIO DE CAMARGO ${ }^{(4,7)}$; LUÍS REYNALDO FERRACCIÚ ALLEONI ${ }^{(5,7)}$
}

\begin{abstract}
RESUMO
O conhecimento das cargas elétricas, permanente e variável, é fundamental para a compreensão e previsão do destino de elementos químicos no solo. Foram investigadas propriedades de carga de superfície de dois Latossolos Vermelhos acriférricos, dois Latossolos Amarelos ácricos e um Nitossolo Vermelho eutroférrico, usado como referência, por apresentar carga predominantemente permanente. Essas amostras foram investigadas pelo método da adsorção do íon césio $\left(\mathrm{Cs}^{+}\right)$, que mede a carga estrutural permanente $\left(\sigma_{\mathrm{O}}\right)$. O método baseia-se na preferência de sítios siloxanos de superfície para $\mathrm{Cs}^{+}$sobre $\mathrm{Li}^{+}$e de grupos de superfície ionizáveis de menor seletividade ao íon $\mathrm{Cs}^{+}$. Nos Latossolos acriférricos, a carga permanente diminuiu à medida que o índice de intemperização (Ki) diminuiu. O método da adsorção de césio quantificou significativa carga permanente, mesmo em solos altamente intemperizados.
\end{abstract}

Palavras-chave: carga estrutural, solo ácrico, adsorção, Latossolos.

\section{ABSTRACT \\ METHOD OF CESIUM ADSORPTION FOR DETERMINATION OF STRUCTURAL CHARGE IN HIGHLY WEATHERED SOILS}

The knowledge of permanent and variable charge is of high importance to a better understanding of the fate of chemical elements in soil. Four Brazilian Oxisols presenting acric character were investigated by an ion adsorption method that measures the structural charge density $\left(\sigma_{\mathrm{O}}\right)$ and were compared to an Alfisol (NV), which had predominantly permanent charge. The method is based on the preference of siloxane surface sites for cesium over lithium and on the lower selectivity of ionizable surface group for the ion cesium. In the Acrudoxes, the permanent charge decreased as the weathering index (Ki) decreased. The cesium adsorption method quantified significant amounts of structural charge, even in highly weathered soils.

Key words: electric charge, acric soil, adsorption, Oxisols

(1) Parte da Tese de Doutorado da primeira autora apresentada à ESALQ/ USP, Piracicaba (SP). Recebido para publicação em 2 de abril e aceita em 1.o de outubro de 2004.

(2) Departamento de Solos e Engenharia Rural, UFMT/FAMEV, Av. Fernando Corrêa da Costa s/n.o, 78060-900 Cuiabá (MT). E-mail: oscsan@uol.com.br

(3) Escola de Engenharia de Piracicaba, Rua Monsenhor Martinho Salgot, 560, 13414-900 Piracicaba (SP).

(4) Centro de Solos e Recursos Ambientais, IAC, Caixa Postal 28, 13001-970- Campinas (SP).

(5) Departamento de Solos e Nutrição de Plantas, ESALQ/USP, Caixa Postal 09, 13418-900 - Piracicaba (SP).

(6) Bolsista CAPES.

(7) Bolsista CNPq. 


\section{Introdução}

Os constituintes dos solos podem ser classificados em dois grupos, aqueles com cargas estruturais ou permanentes (principalmente argilominerais) e aqueles com cargas variáveis (óxidos, hidróxidos e matéria orgânica). As cargas estruturais ou permanentes $\left(\sigma_{O}\right)$ estão sempre operantes, pois se desenvolvem na superfície da partícula sólida do solo por substituição iônica. O conhecimento da carga elétrica permanente $\left(\sigma_{\mathrm{O}}\right)$, como componente de carga superficial das partículas do solo, é fundamental para o entendimento e previsão do destino dos elementos químicos no solo. $\mathrm{O}$ valor de $\sigma_{\mathrm{O}}$ também é necessário para as determinações dos demais componentes de densidade de carga de superfície e dos pontos de carga zero dos solos (SPOsito, 1992).

ANDERSOn e Sposito (1991) propuseram um método para determinar a carga estrutural permanente $\left(\sigma_{\mathrm{O}}\right)$, em solos com elevada quantidade de carga estrutural, que se fundamenta na alta seletividade que o íon $\mathrm{Cs}^{+}$tem para com os filossilicatos $2: 1$, em vista da formação de complexos de esfera interna nos poros ditrigonais das superfícies de siloxanas desses minerais. Essa seletividade é aumentada no sistema em que o cátion trocador é o $\mathrm{Li}^{+}$e a secagem do material adsorvente aumenta a força de formação do complexo de esfera interna entre o $\mathrm{Cs}^{+}$e a carga estrutural mineral. Em seqüência à secagem, promovese uma troca iônica com o $\mathrm{Li}^{+}(\mathrm{LiCl})$ para extrair o $\mathrm{Cs}^{+}$ dos grupos funcionais hidroxila e por último remove-se o $\mathrm{Cs}^{+}$adsorvido por troca com o cátion amônio $\left(\mathrm{NH}_{4}{ }^{+}\right)$ do acetato de amônio $\left(\mathrm{NH}_{4} \mathrm{OAc}\right)$, que tem a capacidade de penetrar nos poros ditrigonais das superfícies de siloxanas.

Esse método envolve procedimentos de adsorção de metais (método do Cs) e foi aplicado com muito sucesso por ANDERSON e SPOSITO (1991), CHOROVER (1993), Chorover e Sposito $(1993,1995)$ e, em solos brasileiros, por Fontes e Sposito (1995) e Peixoto (1995 a,b).

O objetivo da presente nota foi validar o método da adsorção do césio para quantificar a carga estrutural permanente em solos altamente intemperizados, descrevê-lo com detalhe e verificar sua sensibilidade.

\section{Material e Métodos}

O método tem a molalidade $(\mathrm{k}=$ mol de soluto por quilograma de solução) como escala de concentração. A utilização da molalidade permite o cálculo direto do número de moles de um soluto numa pasta de solo ou suspensão quando a massa da pasta ou da suspensão é conhecida. O método original adota uma massa de terra de $35 \mathrm{~g}$ para $240 \mathrm{~g}$ de solução de $\mathrm{CsCl}$ 0,5 mol kg-1 de solução. Entretanto, devido ao elevado preço do cloreto de césio, utilizou-se uma redução proporcional a dez vezes às referidas massas.

Foram utilizadas amostras coletadas a duas profundidades, superficial $(0$ a $20 \mathrm{~cm})$ e subsuperficial na maior expressão do horizonte $B$ de cinco solos: dois Latossolos Vermelhos acriférricos (LVwf-1 e LVwf-2), dois Latossolos Amarelos, um ácrico (LAw) e outro ácriférrico (LAwf), e um Nitossolo Vermelho eutroférrico (NVef), incluído propositalmente como um marco de comparação de solo com material de origem semelhante, mas num estádio de evolução menos adiantado. A descrição e a caracterização mais detalhadas dos solos encontram-se em ALLEONI e CAMARGO (1994).

Para determinar a carga estrutural, pesam-se 3,5 g de amostra de solo em tubos de centrífuga de policarbonato de $50 \mathrm{~mL}$. Adicionam-se $24 \mathrm{~g}$ da solução de $\mathrm{CsCl}$ 0,5 mol kg-1 de solução, agitando-se por 30 minutos em um agitador horizontal, retirando a fração orgânica leve em suspensão com o auxílio de um bastão de vidro. A seguir, centrifuga-se por 35 minutos com força centrífuga relativa (FCR) de $9.820 \mathrm{~g}$, descartando-se a solução sobrenadante. Cabe esclarecer que FCR é a força $(g)$, relativa à gravidade da Terra, aplicada para uma suspensão de partícula durante a centrifugação. Está relacionada à velocidade $(\mathrm{rpm})$ por esta equação: $\mathrm{FCR}=11,17 \times$ raio $(\mathrm{cm}) \mathrm{x}$ (rpm2/1000).

Para reduzir a concentração do excesso de íons, lavam-se as amostras três vezes com cloreto de césio; nas duas primeiras lavagens, adicionam-se 20 g da solução de $\mathrm{CsCl} 0,1 \mathrm{~mol} \mathrm{~kg}^{-1}$ de solução, agita-se por 30 minutos, centrifuga-se em $9.820 \mathrm{~g}$ por $35 \mathrm{~min}$ e descarta-se o sobrenadante. Na terceira lavagem, adicionam-se $20 \mathrm{~g}$ da solução de $\mathrm{CsCl} 0,05 \mathrm{~mol} \mathrm{~kg}^{-1}$ de solução, agita-se por 30 minutos, centrifuga-se na mesma FCR descrita anteriormente e descarta-se a solução sobrenadante.

Após a terceira e última lavada, homogeneizam-se as pastas de terra remanescentes nos tubos da centrífuga e retiram-se subamostras de $0,5 \mathrm{~g}$ das amostras em triplicata, transferindo-se para o cadinho de porcelana, e colocadas a secar por 48 horas a $110{ }^{\circ} \mathrm{C}$, para posterior determinação do conteúdo de água na pasta de terra. Com auxílio dessa umidade, determina-se MPasta do solo seco.

Após a secagem, triplicatas de 0,35 g de MPasta de solo seco de cada amostra de pasta de terra saturada com $\mathrm{CsCl}$ são transferidas para tubos de 
centrífuga de $50 \mathrm{~mL}$, previamente pesados, e suspensas em $3,5 \mathrm{~g}$ de solução de $\mathrm{CsCl} 0,05 \mathrm{~mol} \mathrm{~kg}^{-1}$ a pH $6,0 \pm 0,1$. O ajuste de $\mathrm{pH}$ é feito com soluções de $\mathrm{CsOH}$ ou de $\mathrm{HCl}$ na concentração de $0,05 \mathrm{~mol} \mathrm{~kg}^{-1}$ de solução. Agitam-se as suspensões por 60 minutos em agitador horizontal e, então, centrifugam-se $8.820 \mathrm{~g}$ por 30 minutos, descartando-se as soluções sobrenadantes. Para um solo de textura argilosa a muito argilosa, a MPasta de solo seco utilizada para a tomada de umidade deve ser de 0,8 a 1,0 g, a fim de garantir a obtenção da massa da pasta seca de trabalho de $0,35 \mathrm{~g}$.

Lavam-se as amostras de solo com $30 \mathrm{~g}$ de etanol $(\mathrm{EtOH})$ a $95 \%(\mathrm{v} / \mathrm{v})$ a fim de reduzir a concentração de césio entranhado e formar os complexos de esfera interna entre o íon césio e as superfícies siloxanas. Na seqüência, as amostras passam em banho ultrasônico por 5 minutos, são agitadas por três vezes em vortex à velocidade máxima durante 10 segundos e passam em outro banho ultrasônico por 5 minutos. Centrifugam-se as suspensões etanólicas a $8.820 \mathrm{~g}$ por 30 minutos e descartam-se as soluções sobrenadantes. Essa lavagem deve ser repetida (duas lavagens foram suficientes) até que nenhum cloreto seja detectado pelo teste com solução de $\mathrm{AgNO}_{3} 0,01 \mathrm{~mol} \mathrm{~kg} \mathrm{~kg}^{-1}$ de solução. Destampam-se os tubos de centrífuga contendo as amostras de solo remanescentes, secando-os a $65{ }^{\circ} \mathrm{C}$ por 48 horas em estufa.

Na seqüência, deslocam-se os íons césio dos grupos funcionais ionizáveis. Para tanto, ressuspendem-se as amostras de solos secos em $30 \mathrm{~g}$ da solução de $\mathrm{LiCl}$ 0,01 mol kg-1 a pH 6,0. Agitam-se as suspensões por $30 \mathrm{~min}$. em agitador horizontal e centrifugam-nas a $8.820 \mathrm{~g}$ por $60 \mathrm{~min}$. Transferem-se as soluções sobrenadantes para recipientes plásticos, previamente pesados, e registram-se as massas dos extratos de LiCl. Pesam-se os tubos de centrífuga contendo os solos remanescentes e soluções entranhadas (MT+pasta do solo seco + sobren.), a fim de quantificar a massa de solução entranhada (MLi Entr). O termo MLi Entr (eq.1) é determinado como:

MLi Entr $=$ MT+Pasta do solo seco + sobren MT - M Pasta do solo seco

A seguir, extrai-se o íon césio dos sítios com carga estrutural, adicionando-se $30 \mathrm{~g}$ da solução de acetato de amônio $\left(\mathrm{NH}_{4} \mathrm{OAc}\right) 1,0 \mathrm{~mol} \mathrm{~kg}{ }^{-1}$ de solução às amostras de solo remanescentes nos tubos; agitamse as suspensões por 30 minutos em agitador horizontal e centrifugam-nas a $3.444 \mathrm{~g}$ por 15 minutos. As soluções sobrenadantes são então transferidas para frascos plásticos de $250 \mathrm{~mL}$, pré-pesados. Repetem-se as extrações por três vezes e então, combinam-se todas as soluções extraídas com $\mathrm{NH}_{4} \mathrm{OAc}$, formando uma solução $\left(\mathrm{MNH}_{4} \mathrm{EXT}\right)$, que é pesada e armazenada para análise posterior.
Caso os procedimentos de saturação com as diferentes concentrações de soluções de césio não possam continuar no mesmo dia, sugere-se que as pastas de solo fiquem no tubo de centrífuga sem solução, e mantidas em geladeira de um dia para o outro. Cada adição de solução no tubo contendo pasta de solo remanescente deve ser feita aos poucos, agitando-se no agitador vortex, até que seja toda dissolvida e, posteriormente, completa-se com a massa de solução restante.

As determinações de $\mathrm{Cs}^{+}$nos extratos de $\mathrm{LiCl}$ e de $\mathrm{NH}_{4} \mathrm{OAc}$ podem ser feitas por espectrofotometria de emissão atômica, no comprimento de onda de 852,1 $\mathrm{nm}, 1,0 \mathrm{~nm}$ de largura de fenda, em chama de aracetileno. A curva é preparada com base na massa da solução-estoque de $\mathrm{CsCl}$ 0,05 mol kg-1 de solução nas mesmas matrizes de soluções de $\mathrm{LiCl}$ e $\mathrm{NH}_{4} \mathrm{OAc}$. Todas as amostras, padrões e diluições devem conter potássio como $\mathrm{KCl}\left(5 \mathrm{~g} \mathrm{~kg}^{-1}\right.$ de $\left.\mathrm{K}^{+}\right)$, adicionado como supressor da ionização do $\mathrm{Cs}^{+}$na chama.

A carga variável, $\mathrm{sH}\left(\mathrm{mol}_{\mathrm{c}} \mathrm{kg}^{-1}\right.$ de solo), é determinada por meio da quantidade de $\mathrm{Cs}^{+}$trocável liberada da superfície, após equilíbrio da amostra com $\mathrm{LiCl}$ (equação 2):

$$
-\sigma_{H}=\kappa_{C s}(\text { Li sobr }) \times \frac{M_{\text {Li adicion } .}}{M_{\text {Pasta do solo seco }}}
$$

em que: kCs (Li sobr) é a molalidade de $\mathrm{Cs}^{+}$ na solução sobrenadante; MLi adicion. é a massa da solução de $\mathrm{LiCl}$ adicionada [MLi Extrato (massa da solução sobrenadante) + MLi Entr (solução entranhada após centrifugação)], e MPasta do solo seco é a massa da pasta seca do adsorvente usado quando do processo da adsorção.

A carga permanente, so $\left(\mathrm{mol}_{\mathrm{c}} \mathrm{kg}^{-1}\right.$ de solo), é calculada como excesso de Cs+ retido na carga de superfície específica relativa, seguindo a troca $\mathrm{Li}^{+} \rightarrow$ $\mathrm{Cs}^{+}$(ANDERSOn e SPOSITO, 1991) - equação 3:

$$
-\sigma_{o}=n \operatorname{CsTot}\left(\mathrm{NH}_{4} \text { Ext }\right){ }^{-M} \text { Li Entr }{ }^{\times \kappa} \operatorname{Cs}(\text { Li sobr })
$$

em que: nCs Tot $\left(\mathrm{NH}_{4} \mathrm{EXT}\right)$ é o número total de mols de $\mathrm{Cs}^{+}$do solo extraído pelo $\mathrm{NH}_{4} \mathrm{OAc}$ por unidade de massa do adsorvente seco; $\mathrm{ME}(\mathrm{Li})$ é a massa da solução de $\mathrm{LiCl}$ entranhada por unidade de massa do adsorvente seco. O termo nCs Tot $\left(\mathrm{NH}_{4} \mathrm{EXT}\right)$ da equação 4 é calculado da seguinte forma:

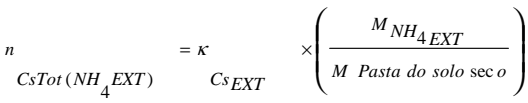

em que: kCs EXT é a molalidade do Cs na solução extratora $\mathrm{NH}_{4} \mathrm{OAc}$. $\mathrm{MNH}_{4}$ EXT é a massa da solução extratora de $\mathrm{NH}_{4} \mathrm{OAc}$. 
A densidade da carga total de superfície, $\sigma_{\text {TOTAL }}$ (eq. 5) (molc kg-1 de solo) é calculada como a soma de $\mathrm{sO}$ e $\mathrm{sH}$ assim:

$$
\sigma_{\mathrm{O}}+\sigma_{\mathrm{H}}=\sigma_{\mathrm{TOTAL}}
$$

\section{Resultados e Discussão}

Os valores de carga permanente dos solos (Tabela 1), concordam com os valores obtidos por Chorover e Sposito (1993) (8 - $21 \mathrm{mmol}_{\mathrm{c}} \mathrm{kg}^{-1}$ de solo), Pеiхото (1995) (7 - 38 mmol $_{\mathrm{c}} \mathrm{kg}^{-1}$ de solo) e FONTES e SPOSITO (1995) (8 - $37 \mathrm{mmol}_{\mathrm{c}} \mathrm{kg}^{-1}$ de solo). O NVef apresentou carga permanente quase cinco vezes superior às dos demais solos. A razão dessa grande diferença pode ser a constituição mineralógica, uma vez que os Latossolos continham teores de gibbsita quatro a cinco vezes maiores que os do NVef, que por sua vez apresentaram teores mais elevados de caulinita e minerais 2:1 (VHE cloritizada) + minerais mal cristalizados (Alleoni e CAMARGo, 1994; WeBer, 2000).

A carga variável correspondeu, em média, a $70 \%$ da carga total nas camadas superficiais dos solos, com valor mínimo de $55 \%$ para o NVef e máximo de $77 \%$ para o LAwf . Em média, o valor de $\sigma_{\mathrm{H}}$ entre os horizontes A e B diminuiu 71\%, acompanhando uma queda média de 3,5 vezes no teor de carbono em profundidade. É realçado o importante papel que a matéria orgânica exerce na capacidade de troca de íons, corroborando as observações de RAIJ e PEECH (1972). Mesmo no horizonte B dos Latossolos a carga variável é de duas a três vezes maior que a permanente, o que comprova o predomínio de carga dependente de $\mathrm{pH}$, característica de material mais intemperizado.

À medida que o índice de intemperismo diminui, as cargas permanentes também diminuem, fato comprovado com o comportamento do NVef em relação aos solos ácricos estudados, em que o referido solo apresentou maior quantidade de carga permanente. Para todos os solos, a carga variável na camada superficial foi maior que em profundidade, demonstrando que houve grande participação da matéria orgânica na geração dessas cargas. O método foi capaz de detectar significativa quantidade de cargas permanentes em solos altamente intemperizados.

Os valores da carga total seguiram a tendência das cargas variáveis e das permanentes, isto é, decresceram em profundidade. Tanto em superfície, quanto em subsuperfície, o NVef apresentou maior $\sigma_{\text {TOTAL, }}$, o LVwf- 1 , a menor.

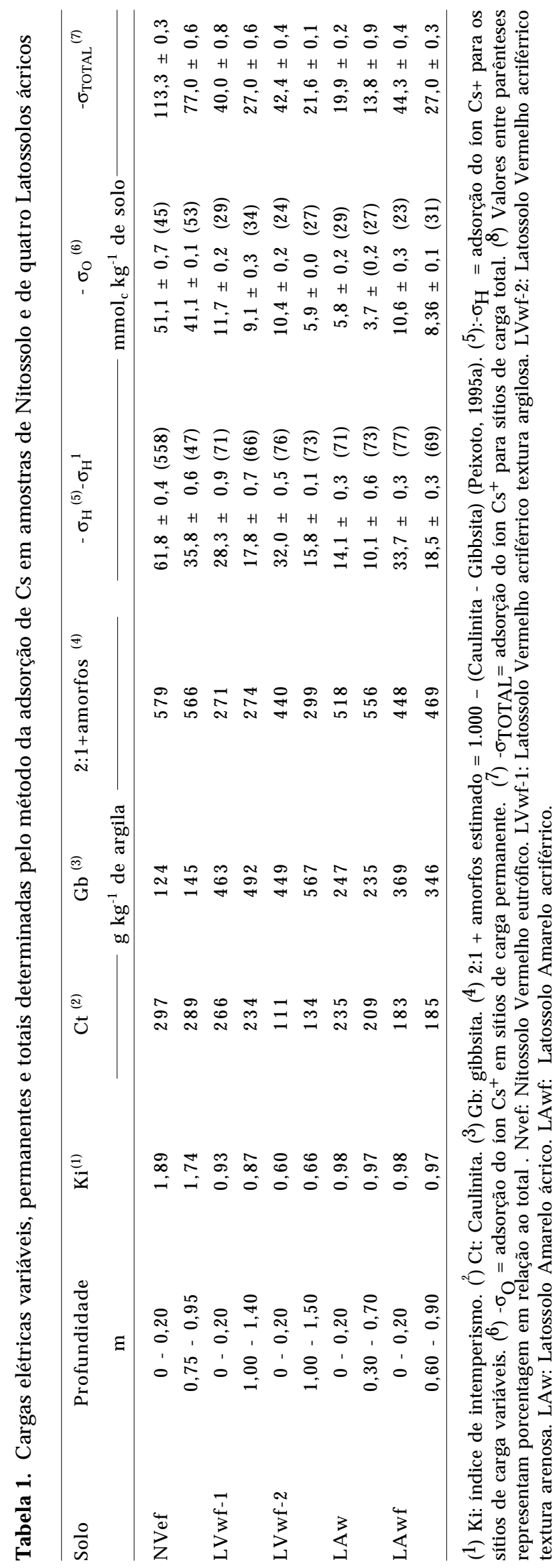

Bragantia, Campinas, v.64, n.1, p.109-113, 2005 


\section{Referências}

ALLEONI, L.R.F.; CAMARGO, O.A. Pontos de efeito salino nulo de Latossolo ácricos. Revista Brasileira de Ciência do Solo, Campinas, v.18, p.175-180, 1994.

ANDERSON, S.J.; SPOSITO, G. Cesium adsorption methods for measuring accessible structural surface charge. Soil Science Society of America Journal, Madison, v.55, p.1569-1576, 1991.

CHOROVER, J.; SPOSITO, G. Surface charge characteristics of kaolinitic tropical soils. Geochimica et Cosmochimica Acta, Elmford, v.59, p.875-884, 1995.

CHOROVER, J.; SPOSITO, G. Measurement of surface charge components: Technical Reports. Berkeley: University of California, 1993. 48p. (NSF grant EAR 9221258).

FONTES, M.P.F.; SPOSITO, G. Medição da densidade de carga estrutural acessível em Latossolos brasileiros com diferentes mineralogias. In: CONGRESSO BRASILEIRO DE CIÊNCIA DO SOLO, 25., Viçosa, 1995. Anais... Viçosa-MG: Universidade Federal de Viçosa/Sociedade Brasileira de Ciência do Solo, 1995. v.1, p.292-294.
PEIXOTO, R.T.G. Surface chemical properties of Oxisols derived from Paraná basalt (Brazil). 1995a, 188p. Thesis (Ph.D.) - Graduate School of the Ohio State University, Ohio.

PEIXOTO, R.T.G., TRAINA, S.J.; BIGHAM, J.M. Propriedades químicas de superfície em função da composição mineral e matéria orgânica em Latossolos derivados de basalto no Paraná. In: CONGRESSO BRASILEIRO DE CIÊNCIA DOSOLO, 25., Viçosa, 1995. Anais... Viçosa-MG: Universidade Federal de Viçosa/Sociedade Brasileira de Ciência do Solo, 1995 b. v.1, p.298-300.

RAIJ, B. van; PEECH, M. Electrochemical properties of some Oxisols and Alfisols of the tropics. Soil Science Society of America Proceedings, Madison, v.36, p.587-593, 1972.

SPOSITO, G. Characterization of particles charge. In: BUFFLE, J.; van LEEUVEN, H. (Ed.). Environmental particles. Boca Raton: IUPAC Publications in Environmental and Analytical Chemistry, 1992. v.1, p.291-314.

SPOSITO, G. The chemistry of soils. New York: Claredon Press, 1989. 262p.

WEBER, O.L.S. Cargas elétricas de superfície e seletividade catiônica de solos com carga variável medidas pelo método da adsorção de césio. 2000. 155 f. Tese (Doutorado). Escola de Agricultura "Luiz de Queiroz", Universidade de São Paulo, Piracicaba. 